\title{
ORIGINAL RESEARCH

SHORT TERM EFFECT OF MULLIGAN'S MOBILIZATION
VERSUS KINESIO TAPING ON KNEE PAIN AND DISABILITY
FOR OSTEOARTHRITIS OF KNEE

\author{
${ }^{1}$ Priyesh P. Malgaonkar \\ ${ }^{2}$ Sai Kumar .N \\ ${ }^{*}$ Vinod Babu .K \\ ${ }^{4}$ Syed Rais Rizvi
}

\section{ABSTRACT}

Background: Mulligan's mobilization and Kinesio taping treatment techniques found to be effective on improving pain and functional disability for osteoarthritis of knee. Hence the purpose is to compare the effect of Mulligan's mobilization and kinesio taping on improvement of pain and functional disability in subjects with osteoarthritis of knee.

Method: An experimental study design, 40 subjects with osteoarthritis of knee joint randomized 20 subjects each into Mobilization Group and Taping Group. Mobilization Group was treated with Mulligan's Mobilization and Taping Group was treated with Therapeutic Kinesio Taping thrice a week for 2 weeks. Outcome measurements such as Visual analog scale (VAS) for pain, Western Ontario and McMaster Universities Osteoarthritis Index (WOMAC) for functional disability was measured before and after 2 weeks post intervention.

Results: Analysis using Paired 't' test and Wilcoxon signed rank test found that there is a statistically significant improvement in VAS and WOMAC within the group. Comparative analysis using Independent ' $t$ ' test and Mann Whitney $U$ test found there is a statistically significant difference in postintervention means between the groups.

Conclusion: The study concluded that both Mulligan's Mobilization and Kinesio Taping techniques significantly shown short term effect on improvement of pain and functional disability for subjects with osteoarthritis of knee. However, there is no statistically significant difference in short term improvements between Mulligan's Mobilization and Kinesio Taping. Among both, Mulligan's Mobilization technique found clinically more effective with greater percentage of improvement than Kinesio Taping technique.

Key words: Osteoarthritis, Knee, Mulligan's Mobilization, Therapeutic Kinesio Taping, Pain, functional Received $16^{\text {th }}$ September 2014, revised $01^{\text {st }}$ October 2014, accepted $03^{\text {rd }}$ October 2014

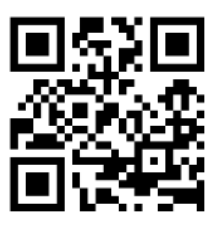

www.ijphy.org

${ }^{1}$ MPT Student,

${ }^{2}$ Professor \& Principal,

${ }^{4}$ Assistant Professor in Physiotherapy.

K.T.G. College of Physiotherapy and

K.T.G Multi-speciality Hospital.

Bangalore. India.
DOI: 10.15621/ijphy/2014/v1i4/54566

\section{CORRESPONDING AUTHOR}

*3 Vinod Babu .K, MPT

Assistant Professor,

K.T.G. College of Physiotherapy and

K.T.G. Multi Speciality Hospital,

Bangalore-560 091, India.

e-Mail: vinodbabupublications@gmail.com; malgaonkar.priyesh@gmail.com 


\section{INTRODUCTION}

Osteoarthritis (OA) is a chronic degenerative disorder of multifactoral etiology characterized by loss of articular cartilage, hypertrophy of bone at the margins, subchondral sclerosis and range of biomechanical and morphological alteration of the synovial membrane and joint capsule. ${ }^{1} \mathrm{OA}$ is the most frequent joint disease with prevalence of $22 \%$ to $39 \%$ in India. ${ }^{2-4}$ Worldwide estimates indicate that $9.6 \%$ of men and $18 \%$ of women $\geq 60$ years have symptomatic OA. ${ }^{5}$ The primary complains of patients suffering from OA knee are pain, stiffness, instability and loss of function. ${ }^{6}$

Mulligan's Movement with Mobilization (MWM) is a manual therapy technique in which a manual force usually in the form of a therapist-applied pain-free accessory joint glide applied with active movement of the gilding segment and sustained while a previously impaired action (e.g. painful reduced movement, painful muscle contraction) is performed. $^{7,8}$ MWM found more effective in improving pain, joint stiffness, range of motion, and walking distance in patients with osteoarthritis of the knee. ${ }^{9,10}$ The mechanisms by which MWM achieves pain relief in OA knee are due to biomechanical effect correcting positional fault ${ }^{8,10}$; and neurophysiological effect in which changes in central and descending pain processing mechanisms. ${ }^{11-13}$

Kinesio taping has been widely used by therapists as an aid for prophylaxis and rehabilitation for many years and systematic reviews found its effectiveness on musculoskeletal conditions. ${ }^{14}$ Kinesio tape (KT) is a thin, cotton, porous fabric with acrylic adhesive that is non medicated and latex-free. ${ }^{15,16}$ In osteoarthritis of knee kinesio tape application aligns the knee in more stable position, reduces stress and strain on the soft tissue surrounding the knee and improves osteoarthritis symptoms. ${ }^{17}$

Studies have been shown that both Mulligan's mobilization and Kinesio tape treatment techniques proved short term effective method of treatment on improving pain and functional disability for subjects with osteoarthritis of knee. ${ }^{17}$, 18, 19 Therefore, the present study with research question 'whether there is difference in short term effect of MWM and kinesio taping on improving pain and functional disability for subjects with osteoarthritis of knee? Hence, the purpose of study with objective is to compare the effect of MWM and kinesio taping on improving pain and functional disability for subjects with osteoarthritis of knee. It was hypothesised that there will be significant difference between effect of Mulligan's mobilization and kinesio taping on improvement of pain and functional disability in subjects with osteoarthritis of knee.

\section{MATERIALS AND METHODS}

An experimental study design with two groupmobilization and taping group. As this study involved human subjects the Ethical Clearance was obtained from the Ethical Committee of KTG College of Physiotherapy and K.T.G. Hospital, Bangalore as per the ethical guidelines for Biomedical research on human subjects. The study was registered with University (RGUHS) No. : 09_T031_39004. The study was conducted at K.T.G Multi Speciality Hospital, Bangalore. Total 40 Subject $(\mathrm{n}=40)$ with Osteoarthritis of knee were recruited by Simple random sampling method using Group marked 40 paper slips in closed envelopes, accordingly subjects were randomly allocated, 20 subjects into Mulligan's group and 20 into Taping group.

Subjects included were history of knee osteoarthritis since two years, ${ }^{20}$ clinically diagnosed as OA knee with grade 3 changes on radiological evaluation using Kellgren and Lawrence system, clinical finding of OA knee with three of the criteria plus knee pain based on American college of rheumatology criteria for classification and reporting of osteoarthritis of knee joint (age $>50$ years, stiffness $<30 \mathrm{~min}$, crepitus, bony tenderness, bony enlargement, no palpable warmth), ${ }^{21}$ both male and female subjects, age group between 50 to 60 years $^{21,23}$, subject who were willing to participate. Subjects excluded were with osteoarthritis of hip, ankle and foot, Serious concomitant systemic disease, Intra articular corticosteroid or hyaluronic injection during past six months, subjects who undergone any lower limb surgery, osteoarthritis of knee with deformity, subjects who were on any kind of medicine such as analgesics for knee pain other than their routine medication. Total duration of treatment was carried for 2 weeks, 3 sessions per week. All the subjects fulfilling the inclusion criteria were informed about the study and a written informed consent was taken.

Procedure for intervention for Mobilization Group: Treated with Mulligan's Mobilization ${ }^{18}$

Selection of glide: MWM consisted of a sustained manual glide of the tibia (either medial, lateral, anterior, posterior or rotation) during active knee flexion and extension. Each subject was tested with sustained manual glides in each of the possible directions during active knee flexion and extension in supine lying. Frontal plane glides were tested first and then sagittal plane glides followed by rotation. The glide direction that reduced pain to 
the minimum level and improved the affected range of knee motion most was chosen as the glide for the MWM treatment technique. Overpressure was included at end range if ROM was pain-free. If pain was not present in supine lying, then the glide direction for the MWM treatment technique was assessed in a weight-bearing position in a similar manner. If in supine lying more than one glide direction had similar beneficial effects, then these assessments was repeated in weight-bearing to identify the most effective glide direction for the treatment technique.

Application of MWM: At the first intervention, a MWM was applied (three sets of 10 repetitions) during active knee flexion and extension. Initially the pain-free manual glide force on the tibia was applied with the knee resting in a mid range position. The glide force was sustained while the subject performed 10 repetitions of self-paced active full range knee flexion and extension. Either of the two protocols was used depending on the assessment of the subject's pain during active knee flexion and extension in lying: 1 . For subjects with pain during active knee flexion and extension in lying, the technique was performed initially in lying. The technique was progressed to weightbearing positions when the movement in lying becomes pain-free. The subject was taught a self applied MWM in weight-bearing position. 2. For subjects without pain during active knee flexion and extension in lying, MWM was performed in the weight-bearing position. Subjects were similarly instructed for the self-applied MWM in the weight bearing position.

The self-management regime involved at least 20 movement repetitions, performed every 3 hours (or at least four to five times per day) was advised to do compulsorily.

Subjects could perform the MWM exercise more frequently if they experience any increase in pain with daily activities. They were also advised to stop the self-applied MWM if this exercise cause pain or their knee showed signs of increasing inflammation such as swelling, heat or redness greater than pre-treatment levels. On the subsequent reviews, MWM intervention was repeated for 3 sets of 10 repetitions with one minute rest in between each set for six sessions with two days interval. Subjects were treated in lying if they continued to have pain during movement in the non-weight-bearing position. Otherwise, MWM was applied in the weightbearing position. The glide direction was again checked prior to application of the intervention. Subjects self-applied MWM were checked for their correctness at each review.
Procedure for intervention for therapeutic kinesio taping Group: ${ }^{15,16,17}$

The K-tape was applied from origin to insertion for the facilitation of quadriceps muscle. Superior ' $\mathrm{Y}$ ' technique was done. Subject was sitting with affected leg out of the bed and thigh was in flexed position. The application of tape was begun with the kinesio "Y" strip approximately mid thigh over the vastus medialis muscle. It was applied light with (25\% of available) or paper off tension until " $Y$ " in kinesio strip reaches the superior pole of the patella. Glue activation was initiated prior to any further patient movement. Then subject was instructed to flex the knee to maximum flexion. The tails of the kinesio strip was then applied around the medial and lateral border of the patella. The tails were applied with light (25\% of available) or paper off tension. The tip of the tail ended with no tension on the tibial tuberosity. Again initiation of glue activation was done prior to any further patient movement. Second tape was applied for mechanical correction. It consists of application of mechanical correction with tension on the tail of "I" strips. With this technique the tension was placed on the tape to use "the recoil effect" of the elastic quality of the kinesio tape to create proprioceptive tension. The base of the "I" strip was applied on the medial joint line when knee was in relaxed position. With one hand the base was held to ensure no tension been added during application. Then tail of "I" strip was applied with moderate (50\% of available) and inward pressure along the inferior pole of the patella. The last approximately one inch of the tail was applied with no tension on lateral joint line. All subjects were instructed to wear tape for two days and return for review after 24 hours removing tape. Subjects were also instructed to remove tape if they fill itching, heat redness or discomfort. ${ }^{15,16,17}$

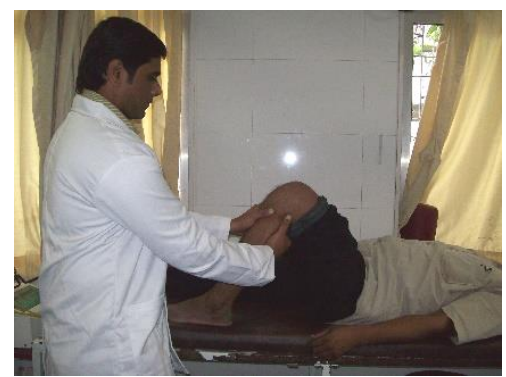

Fig. 1: MWM Rotation glide in supine lying.

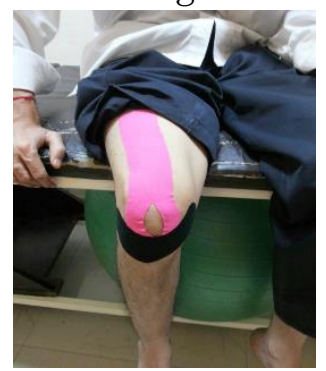

Fig. 2: Kinesio Taping- Post application. 


\section{Outcome Measurements:}

Outcome measurements such as pain and functional disability were measured before and after two weeks of intervention.

1. Visual analogue scale (VAS) to measure intensity of pain: It is a continuous scale which is present as 10 centimetres in length. The scale is most commonly anchored by "no pain" and "pain as bad as it could be". The respondent is asked to place a line perpendicular to the VAS line at the point that represents their pain intensity. Using a ruler, the score was determined by measuring the distance in $\mathrm{cm}$ on 10-cm line. Test-retest reliability has been shown to be good, but higher among literate $(\mathrm{r}$ _ 0.94, $\left.P_{-}{ }_{0} 0.001\right)$ than illiterate patients $\left(\mathrm{r}_{-}\right.$ $\left.0.71, P_{-} 0.001\right) .^{23}$

2. Western Ontario and McMaster Universities Osteoarthritis Index (WOMAC) for measuring severity of functional disability: The functional disability is measured by WOMAC which is self administered, being filled in by patients themselves. It consists of 3 sections with 24 items in total (5 pain, 2 stiffness and 17 for physical function) which produces 3 subscale scores for each section and a total score. The total WOMAC score can be obtained and percent score can be calculated. The test retest reliability for the WOMAC pain subscale had found to vary between 0.77 and 0.86 . Testretest reliability was satisfactory with ICCs of $0.86,0.68$, and 0.89 , respectively. ${ }^{24}$

\section{STATISTICAL METHODS}

Descriptive statistical analysis was carried out in the present study. Out Come measurements analyzed are presented as mean \pm SD. Significance is assessed at $5 \%$ level of significance with $p$ value was set at 0.05 less than this is considered as statistically significant difference. Paired ' $t$ ' test as a parametric and Wilcoxon signed rank test as a non-parametric test have been used to analysis the variables pre-intervention to post-intervention with calculation of percentage of change. Independent' $t$ ' test as a parametric and Mann Whitney $U$ test as a non-parametric test have been used to compare the means of variables between two groups with calculation of percentage of difference between the means. The Statistical software namely SPSS 16.0, Stata 8.0, MedCalc 9.0.1 and Systat 11.0 were used for the analysis of the data and Microsoft word and Excel have been used to generate graphs, tables etc.

\section{RESULTS}

The study was carried on total 40 subjects. In Taping Therapy Group there were 20 subjects with mean age 53.50 years and there were 6 males 14 females were included in the study. In Mobilization Group there were 20 subjects with mean age 52.95 years there were 6 males and 14 females were included in the study. There is no significant difference in mean ages between the groups.

Within the group analysis found that there is a statistically significant change in means of VAS and WOMAC score when means were analyzed from pre intervention to post intervention within Taping and Mobilization groups. Comparative analysis found that there is no statistically significant difference in means of VAS and WOMAC score between Taping and Mobilization groups.

Table 1: Basic Characteristics of the subjects studied

\begin{tabular}{|c|c|c|c|c|}
\hline \multicolumn{2}{|c|}{$\begin{array}{l}\text { Basic Characteristics of the } \\
\text { subjects studied }\end{array}$} & $\begin{array}{l}\text { Taping } \\
\text { Group }\end{array}$ & $\begin{array}{l}\text { Mobilization } \\
\text { Group }\end{array}$ & $\begin{array}{l}\text { Between the groups } \\
\text { Significance }^{a}\end{array}$ \\
\hline \multicolumn{2}{|c|}{$\begin{array}{l}\text { Number of subjects } \\
\text { studied (n) }\end{array}$} & 20 & 20 & -- \\
\hline \multicolumn{2}{|c|}{$\begin{array}{l}\text { Age in years } \\
(\text { Mean } \pm S D)\end{array}$} & $\begin{array}{c}53.50 \pm 2.21 \\
(50-58)\end{array}$ & $\begin{array}{l}52.95 \pm 2.25 \\
(50-58)\end{array}$ & $p=0.861(\mathrm{NS})$ \\
\hline \multirow{2}{*}{ Gender } & Males & 6 & 6 & \multirow{2}{*}{$\mathrm{P}=0.000^{* *}$} \\
\hline & Females & 14 & 14 & \\
\hline \multirow{2}{*}{ Side } & Right & 10 & 10 & \multirow{2}{*}{$\mathrm{P}=1.000(\mathrm{NS})$} \\
\hline & Left & 10 & 10 & \\
\hline
\end{tabular}

a- Pearson Chi-Square 
Table 2: Analysis of pain and functional disability within taping and mobilization groups (Pre to post test analysis)

\begin{tabular}{|c|c|c|c|c|c|c|c|c|}
\hline & \multirow{2}{*}{$\begin{array}{c}\text { Pre } \\
\text { intervention } \\
(\text { Mean } \pm \text { SD) } \\
\text { min-max }\end{array}$} & \multirow{2}{*}{$\begin{array}{c}\text { Post } \\
\text { intervention } \\
(\text { Mean } \pm \mathrm{SD}) \\
\text { min-max }\end{array}$} & \multirow{2}{*}{$\begin{array}{c}\text { Percentage } \\
\text { change }\end{array}$} & \multirow{2}{*}{$\begin{array}{c}\text { Z value }{ }^{b} \\
\text { (Non } \\
\text { parametric) } \\
\text { Significance } \\
\text { p value }\end{array}$} & \multirow{2}{*}{$\begin{array}{c}\mathrm{t}^{\text {value }}{ }^{\mathrm{a}} \\
\text { (Parametric) }^{\text {Paramificance }} \\
\text { p value }\end{array}$} & \multicolumn{2}{|c|}{$\begin{array}{l}\text { 95\% Confidence } \\
\text { interval of the } \\
\text { difference }\end{array}$} & \multirow{2}{*}{$\begin{array}{l}\text { Effect } \\
\text { Size }(r)\end{array}$} \\
\hline & & & & & & Lower & Upper & \\
\hline & \multicolumn{5}{|c|}{ Taping Group } & & & \\
\hline $\begin{array}{c}\text { Visual } \\
\text { analog scale } \\
\text { score in cm }\end{array}$ & $\begin{array}{c}4.89 \pm 1.40 \\
(2.4-7.3)\end{array}$ & $\begin{array}{c}3.03 \pm 1.06 \\
(1.3-5.1)\end{array}$ & $-38.03 \%$ & $\begin{array}{c}-3.924 \\
p<0.000^{* *}\end{array}$ & $\begin{array}{c}14.257 \\
p<0.000^{* *}\end{array}$ & 1.58 & 2.13 & $\begin{array}{c}+0.59 \\
\text { ( Large) }\end{array}$ \\
\hline \multirow[t]{2}{*}{$\begin{array}{l}\text { WOMAC } \\
\text { score in } \\
\text { percentage }\end{array}$} & $\begin{array}{l}38.17 \pm 10.65 \\
(25.00-59.38)\end{array}$ & $\begin{array}{c}22.13 \pm 8.22 \\
(11.46-39.58)\end{array}$ & $-42.02 \%$ & $\begin{array}{c}-3.923^{* *} \\
p<0.000^{* *}\end{array}$ & $\begin{array}{c}14.670 \\
p<0.000^{* *}\end{array}$ & 13.75 & 18.33 & $\begin{array}{c}+0.64 \\
\text { (Large ) }\end{array}$ \\
\hline & \multicolumn{5}{|c|}{ Mobilization Group } & & & \\
\hline $\begin{array}{c}\text { Visual } \\
\text { analog scale } \\
\text { score in cm }\end{array}$ & $\begin{array}{c}5.25 \pm 1.73 \\
(2.7-7.8)\end{array}$ & $\begin{array}{c}2.61 \pm 1.11 \\
(1.2-4.8)\end{array}$ & $-50.28 \%$ & $\begin{array}{c}-3.922 \\
p<0.000^{* *}\end{array}$ & $\begin{array}{c}11.733 \\
p<0.000^{* *}\end{array}$ & 2.16 & 3.10 & $\begin{array}{c}+0.67 \\
\text { ( Large ) }\end{array}$ \\
\hline $\begin{array}{l}\text { WOMAC } \\
\text { score in } \\
\text { percentage }\end{array}$ & $\begin{array}{l}41.14 \pm 10.96 \\
(26.04-60.42)\end{array}$ & $\begin{array}{l}18.28 \pm 6.88 \\
(8.33-35.42)\end{array}$ & $-55.56 \%$ & $\begin{array}{c}-3.923 \\
\mathrm{p}<0.000^{* *}\end{array}$ & $\begin{array}{c}15.532 \\
p<0.000^{* *}\end{array}$ & 19.78 & 25.94 & $\begin{array}{c}+0.78 \\
\text { ( Large) }\end{array}$ \\
\hline
\end{tabular}

** Statistically Significant difference p<0.05; NS- Not significant; a. Pared t test. b. Wilcoxon Signed Rank Test

Table 3: Comparison of means of pain and functional disability between Taping and Mobilization Groups

\begin{tabular}{|c|c|c|c|c|c|c|c|c|}
\hline & \multirow[t]{2}{*}{$\begin{array}{l}\text { Taping Group } \\
(\text { Mean } \pm \text { SD }) \\
\text { min-max }\end{array}$} & \multirow{2}{*}{$\begin{array}{l}\text { Mobilization } \\
\text { Group } \\
(\text { Mean } \pm \text { SD) } \\
\text { min-max }\end{array}$} & \multirow[t]{2}{*}{$\begin{array}{c}\text { Percentage } \\
\text { of } \\
\text { difference }\end{array}$} & \multirow{2}{*}{$\begin{array}{c}\text { Z valueb } \\
\text { (Non } \\
\text { parametric) } \\
\text { Significance } \\
\text { p value }\end{array}$} & \multirow{2}{*}{$\begin{array}{c}\mathrm{t}^{\text {value }}{ }^{\mathrm{a}} \\
\text { (Parametric) }^{\text {Pagnificance }} \\
\text { p value }\end{array}$} & \multicolumn{2}{|c|}{$\begin{array}{c}95 \% \\
\text { Confidence } \\
\text { interval of the } \\
\text { difference }\end{array}$} & \multirow[t]{2}{*}{$\begin{array}{l}\text { Effect } \\
\text { Size r }\end{array}$} \\
\hline & & & & & & Lower & Upper & \\
\hline & \multicolumn{5}{|c|}{ PREINTERVENTION } & & & \\
\hline $\begin{array}{l}\text { Visual analog } \\
\text { scale score in } \\
\mathrm{cm}\end{array}$ & $\begin{array}{c}4.89 \pm 1.40 \\
(2.4-7.3)\end{array}$ & $\begin{array}{c}5.25 \pm 1.73 \\
(2.7-7.8)\end{array}$ & $7.10 \%$ & $\begin{array}{l}Z=-0.690 \\
P=0.490\end{array}$ & $\begin{aligned} & -0.719 \\
P= & 0.476(\mathrm{NS})\end{aligned}$ & -1.37 & 0.65 & $\begin{array}{c}+0.11 \\
\text { (Small) }\end{array}$ \\
\hline \multirow[t]{2}{*}{$\begin{array}{l}\text { WOMAC } \\
\text { score in } \\
\text { percentage }\end{array}$} & $\begin{array}{l}38.17 \pm 10.65 \\
(25.00-59.38)\end{array}$ & $\begin{array}{l}41.14 \pm 10.96 \\
(26.04-60.42)\end{array}$ & $7.49 \%$ & $\begin{array}{l}Z=-0.934 \\
P=0.350\end{array}$ & $\begin{array}{c}-0.868 \\
P=0.391(\mathrm{NS})\end{array}$ & -9.88 & 3.95 & $\begin{array}{c}+0.05 \\
\text { (Small) }\end{array}$ \\
\hline & \multicolumn{5}{|c|}{ POST INTERVENTION } & & & \\
\hline $\begin{array}{l}\text { Visual analog } \\
\text { scale score in } \\
\mathrm{cm}\end{array}$ & $\begin{array}{c}3.03 \pm 1.06 \\
(1.3-5.1)\end{array}$ & $\begin{array}{c}2.61 \pm 1.11 \\
(1.2-4.8)\end{array}$ & $2.82 \%$ & $\begin{array}{c}Z=-1.070 \\
P=0.284\end{array}$ & $\begin{array}{c}1.202 \\
P=0.237(\mathrm{NS})\end{array}$ & -0.28 & 1.11 & $\begin{array}{c}+0.19 \\
\text { (small) }\end{array}$ \\
\hline $\begin{array}{l}\text { WOMAC } \\
\text { score in } \\
\text { percentage }\end{array}$ & $\begin{array}{c}22.13 \pm 8.22 \\
(11.46-39.58)\end{array}$ & $\begin{array}{l}18.28 \pm 6.88 \\
(8.33-35.42)\end{array}$ & $-19.05 \%$ & $\begin{array}{l}Z=-1.478 \\
P=0.350\end{array}$ & $\begin{array}{c}1.608 \\
P=0.116(N S)\end{array}$ & -0.99 & 8.70 & $\begin{array}{c}+0.24 \\
\text { (Small) }\end{array}$ \\
\hline
\end{tabular}

** Statistically Significant difference $p<0.05$; NS- Not significant Whitney U Test a. Independent t test b. Mann- 
Graph 1: Comparison of means of VAS between Taping and Mobilization Groups (PREINTERVENTION)

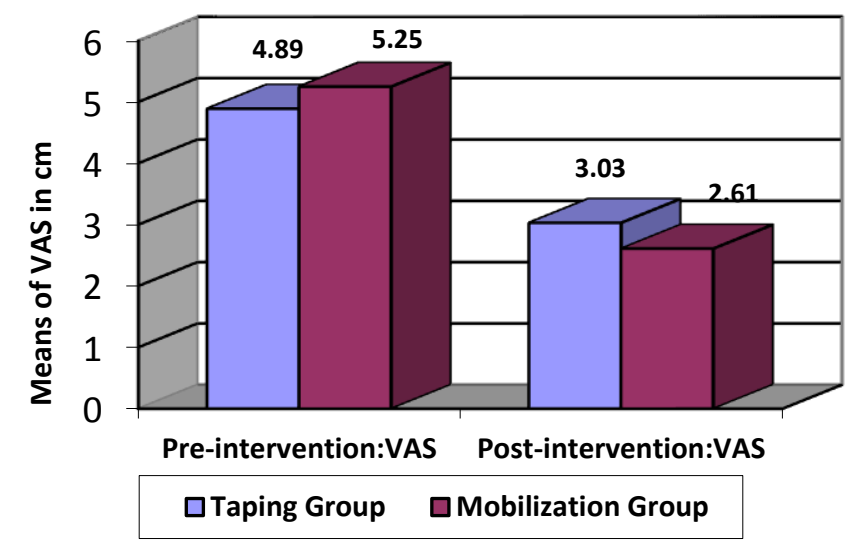

The above graph shows that there is no statistically significant difference in means of Visual analogue score for pain when pre-intervention means were compared between Taping and mobilization groups.

Graph 2: Comparison of means of VAS between Taping and Mobilization Groups (POST INTERVENTION)

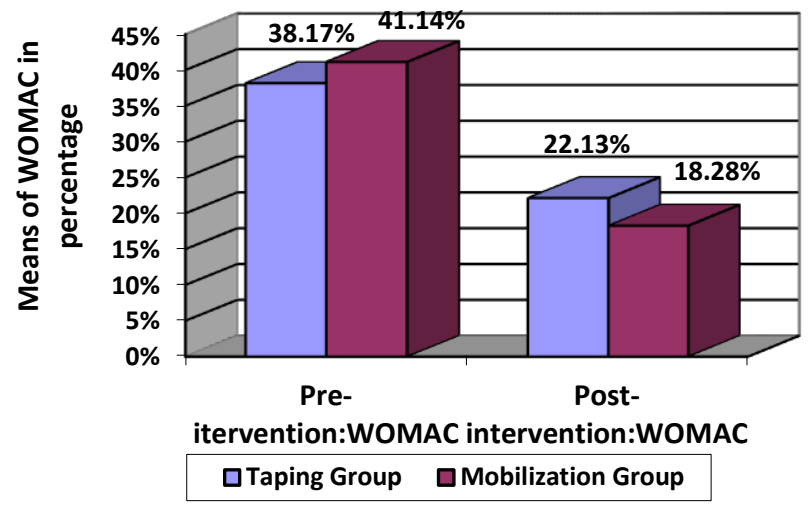

The above graph shows that there is no statistically significant difference in means of WOMAC score when pre-intervention means were compared between Taping and mobilization groups.

\section{DISCUSSION}

It is found that there is no statistically significant difference between Mulligan's Mobilization technique and Kinesio Taping technique on improvement of pain and functional disability for subjects with osteoarthritis of knee. However, the Mobilization Group subjects found greater percentage of improvement than Taping Group subjects when analyzed within the group.

In Mobilization Group, the improvements could be because of biomechanical and neurophysiological mechanisms of MWM. Biomechanically it was proposed that MWM may address joint partner bone alignment i.e. patellofemoral and tibiofemoral joint and correct the positional fault. Neurophysiologically changes in central and descending pain processing mechanisms are probably involved. In addition, the large range of movement used in the application of MWM might alter concentration of inflammatory mediators and result in deactivation of nociceptors activated by such inflammatory mediators, while the pain relief afford by MWM would be associated with improvement of disability level. The MWM is largely conducted in weight-bearing position and patient receives simultaneous feedback of painless joint movements resulting in increased activity level. MWM in a weight bearing position requires muscle activity, which might have resulted in improved motor performance, which would position the patient well to gain long-term benefits from a formal exercise program. In present study, application of knee MWM resulted in significantly positive changes in the knee pain similar to previous studies. Hiroshi Takasaki, et al. concluded in their study that Mulligan's Mobilization of movement is associated with immediate pain relief and improves knee function suggesting its potential as component of early management of osteoarthritis of knee. Evgniya Dimitrova et al. stated that MWM is feasible and efficacious in individuals with knee $\mathrm{OA}$ in reducing pain and improving range of motion. ${ }^{25}$

In Taping Group, the improvement could be because of taping that allows a partial to full range of motion for the applied muscles and joints with different pulling forces to the skin. It is proposed that the tape lifts the skin and increases the spaces between the skin and muscle, hence reducing the localized pressure and helping to promote circulation and lymphatic drainage. As a result, it reduces pain swelling and muscle spasm. Kinesio tape application and positioning of tape align the knee in more stable position and this reduce stress and strain on the soft tissue that surrounds the knee and improved osteoarthritis symptoms. KT is also believed to have several functions; restoring correct muscle function by supporting weakened muscles by facilitation of quadriceps muscle and vastus medialis muscle, reducing congestion by improving the flow of the blood and lymphatic fluid, decreasing pain by stimulating the neurological system and correcting malaligned joints, by relieving muscle spasm. ${ }^{26,27}$ It is also pointed out that KT improves proprioception by the normalization of muscle tone, a reduction in pain, correction of inappropriate position and the stimulating effect on skin receptors. ${ }^{27}$

The findings of KT group have shown similar effects compare to previous studies. Rana S Hinman, et al. found that therapeutic knee taping is an efficacious treatment for the management of 
pain and disability in patients with knee osteoarthritis. S R Akinbo, A M Ojetunde in their study compared the effect of Kinesio taping on Pain and Joint Range of Motion in patients with Knee Joint Osteoarthritis and Knee Sport Injury. They found that there was a significant difference on pain and no significant difference for ROM.

Comparison of pre intervention and post intervention means found statistically no significant difference between Taping and Mobilization groups with small effect size. However the Mobilization Group subjects found greater percentage of change with large effect size in improvement than Taping Group subjects this could be because the Mulligan's Self MWM was taught to the subjects as a home program after the MWM was administered to subjects by the therapist. However, whether the subjects performed the self MWM correctly at home was not being supervised. In contrast, Dr. Kase and Wallis, the inventor of the Kinesio taping, however suggested that Kinesio taping works better if the intervention is cooperated with adequate exercise, therefore lack of exercises could have affected that effectiveness taping. ${ }^{28}$

Based on the findings as per the study objective to test hypothesis the present study found statistically no significant difference in improvement of pain and functional ability between Mulligan's Mobilization and Kinesio Taping Group. Therefore the study is favouring null hypothesis.

Limitations of the study are the subjects with wide range group between 50 to 60 years of age were considered for the study, thus results cannot be generalized to individual age. There was lack of control group, No follow-up sessions were kept after the final treatment due to which the maintenance of the improved outcome or reoccurrence of the condition could not be assessed. Pain and functional disability were studied. But there is lack of objective outcome measures to accurately assess knee joint movement (ROM) and muscle strength. There were no patients who responded to an anterior or posterior glide. This finding corresponds with the clinical experience of Mulligan, who mentioned that the typical direction of beneficial glide for hinge joints was usually medial or lateral. However, the explanation why anterior or posterior glides are not beneficial for patients with knee OA remains unclear.

Recommendation for future research: Studies are needed to find long term effect of Mulligan Mobilization comparing with Kinesio Taping. Further study can be carried taking objective outcome measurements such as ROM and Muscle
Strength in knee pain. Comparison of Mulligan's mobilization with taping can be carried out on other condition where both techniques are indicated.

\section{CONCLUSION}

The study concluded that both Mulligan's Mobilization and Kinesio Taping techniques significantly shown short term effect on improvement of pain and functional disability for subjects with osteoarthritis of knee joint. However, there is no statistically significant difference in short term improvements when compare between Mulligan's Mobilization and Kinesio Taping. Among both, Mulligan's Mobilization technique found clinically more effective with greater percentage of improvement than Kinesio Taping technique. Therefore use of Mulligan's Mobilization technique is recommended over Kinesio Taping technique for treatment of osteoarthritis of knee.

\section{Acknowledgement:}

Authors were expressing their sense of gratitude's to the people who helped and encouraged them for the guidance and completion of this study.

\section{Conflicts of interest: None}

\section{REFERENCES:}

1. Harris ED, Budd RC, Genovese MC et al. Kelley's Textbook of Rheumatology. $7^{\text {th }}$ ed;2005.

2. Chopra A, Patil J, Bilampelly V et al. Methodology and first information report. Journal of Rheumatolology. 1997; 1:145-54.

3. Chopra A, Patil J, Bilampelly V, Relwane J, Tandle HS. Prevalence of rheumatic disease in rural population in Western India: a WHO-ILAR COPCARD study. J Assoc Physicians India. 2001;49:240-6.

4. Mahajan A, Jasrotia DS, Manhas AS, Jamwal SS. Prevalence of major rheumatic disorders in Jammu. JK Science. 2003; 5(2):63-66.

5. Wolf AD, Pfleger B. Burden of Major Musculoskeletal Conditions. Policy and Practice. Special Theme-Bone and Joint Decade 2000-2010. Bulletin of the World Health Organization. 2003; 81 (9): 646-656.

6. Anita Emrani, Hossein Bagheri, Mohhamad Reza Hadian et al. Isokinetic Strength and Functional Status in Knee Ostioarthritis. Journal of Physical Therapy Science 2006; 18(2):107-114.

7. Konstantinou, Foster, Rushton, and Baxter. The use and reported effects of mobilization with movement techniques in low back pain management; a cross-sectional descriptive 
survey of physiotherapists in Britain. Manual Therapy. 2002;7(4):206-214.

8. Brian R. Mulligan. Manual therapy: "NAGS", "SNAGS", "MWMS". 2004.

9. Gail D. Dyle, Nancy E. Henderson, Robert L. Matekal, et al. Effectiveness of Manual Physical Therapy and Exercise in Osteoarthritis of knee joint. - A Randomized, Controlled Trial. Ann Intern Med. 2000;132(3):173-181.

10. Vicenzino, Hall, Hing, and Rivett. Mobilisation with Movement: The Art and the Science. $1^{\text {st }}$ edi; 2011.

11. Paungmali, O'Leary, Souvlis, and Vicenzino. Hypoalgesic and sympathoexcitatory effect of mobilization with movement for lateral epicondylagia. Physical Therapy.2003; 83(4): 374-383.

12. Hall T, Hardt S, Schafer A, Wallin L. Mulligan bent leg raise technique-A preliminary randomized trial of immediate effects after a single intervention. Manual Therapy. 2006; 11(2):130-5.

13. Bill Vicenzino, Aatit Paungmali, Pamela Teys .Mulligan's mobilization-with-movement, positional faults and pain relief: Current concepts from a critical review of literature, Science Direct, Manual Threapy. 12(2):98-108.

14. Kelly $\mathrm{T}$ Basset, Stacey A. Lingaman, Richard F.Ellis .The use and treatment efficacy of kinesio tape in musculoskeletal condition: a systematic review. Newzeland Journal of Physiotherapy.2009; 38(2): 43-84.

15. S R Akinbo, A M Ojetunde. Comparison of the Effect of Kinesiotape on Pain and Joint Range of Motion in Patients with Knee Joint Osteoarthritis and Knee Sport Injury. Nigerian Medical Practitioner.2007; 52 (3):65-69.

16. Fu TC, Wong AM, Pei YC, Wu KP, Chou SW, Lin YC. Effect of kinesio taping on muscle strength in athletes - A pilot study. J Sci Med Sport. 2008; 11(2):198-201.

17. Hinson. Efficacy of knee tape in the management of osteoarthritis of the knee: blinded randomized controlled trial. BMJ. 2003;327:135

18. 33 Hiroshi Takasaki, Toby Hall, Gwaendolen Jull. Immediate and short-term effects of
Mulligan's mobilization with movement on knee pain and disability associated with knee osteoarthritis -A prospective case series. Physiother Theory Pract. 2013;29(2):87-95.

19. Rana S Hinman, Kay M Crossley Jenny McConnell Kim L Bennell. Efficacy of knee tape in the management of osteoarthritis of the knee: blinded randomised controlled trial. BMJ. 2003;327:135.

20. Joern W.-P. Michael, Klaus U Schlüter-Brust, Peer Eysel. The Epidemiology, Etiology, Diagnosis, and Treatment of Osteoarthritis of the Knee. Journal Dtsch Arztebl Int. 2010; 107 (9): 152-162.

21. G Peat, E Thomas, R Duncan, L Wood, E Hay, P Croft. Clinical classification criteria for knee osteoarthritis: performance in the general population and primary care. Ann Rheum Dis. 2006;65(10):1363-1367.

22. American College of Rheumatology Subcommittee on Osteoarthritis Guidelines. Recommendations for the medical management of osteoarthritis of the hip and knee. Arth Rheum. 2000; 43: 1905-15.

23. Leighann Litcher Kelly, e.t al. A systemtic review of measures used to assess chronic musculoskeletal pain in clinical trials. Journal of pain.2007; 8(12):906-913.

24. Salaffi F, Leardini G, Canesi B el al. Relibility and validity of the western Ontario and mc master university (WOMAC) osteoarthritis index in Italian patients with osteoarthritis of knee joint. Osteoarthritis Cartilage. 2003;11(8): 551-60.

25. Evgeniya Dimitrova. Efficacy mobilization with of movement in patient with knee osteoarthritis. Sports Medicine Journal. 2008; 16.

26. Yoshida A, Kahanov L. The effect of kinesio taping on lower trunk range of motions. Res Sports Med. 2007; 15(2):103-12.

27. Słupik A, Dwornik M, Bialoszewski D, Zych E. Effect of kinesio taping on bioelectrical activity of vastus medialismuscle. Preliminary report. Ortop Traumatol Rehabil. 2007; 9(6):644-51.

28. Kase K, Wallis J. The latest Kinesio taping method. Tokyo: Ski-Journal; 2002.

\section{Citation}

Priyesh P. Malgaonkar, Sai Kumar.N, Vinod Babu .K \& Syed Rais Rizvi. (2014). SHORT TERM EFFECT OF MULLIGAN'S MOBILIZATION VERSUS KINESIO TAPING ON KNEE PAIN AND DISABILITY FOR OSTEOARTHRITIS OF KNEE. International Journal of Physiotherapy, 1(4), 233-240. 